\title{
Omental transplantation for neuromyelitis optica
}

\begin{abstract}
I report a 45-year old woman who had a history of neuromyelitis óptica (NMO). She was admitted by bilateral blindness and mydriasis, as well as tetraparesia. The visual evoked potential revealed absence of waves in both eyes. For this reason, she received an omental transplantation on the optic chiasm and left temporal lobe. Three days after surgery, she presented motor improvement in her limbs and later, she presented photophobia, photomotor reflex and to visualize silhouette of people and things. She died 8 days after surgery by bronchopneumonia. These results suggest that in the NMO there is an ischemic component in the optic chiasm and adjacent zones.
\end{abstract}

Volume 6 Issue 2 - 2017

\author{
Hernando Rafael \\ Neurosurgeon, Clínica Santa Mónica, Lima, Peru
}

Correspondence: Hernando Rafael, MD, Bélgica 4II-BIS

Colonia Portales, 33 Mexico city, Mexico, Tel +(5255) 5264 2774;

+(51)991 489 III, Email hrtumi@yahoo.com

Received: January 26, 2017| Published: February 13, 2017

Keywords: neuromyelitis óptica, multiple sclerosis, chiasmatic ischemia

\section{Introduction}

Neuromyelitis optica (NMO), also known as Devic's disease, is a rare inflammatory disease of the central nervous system (CNS) characterized by severe optic neuritis and transverse myelitis, usually with a relapsing course. ${ }^{1-3}$ Multiple sclerosis (MS) and NMO are autoinmune demyelinating diseases of the CNS, having distinct inmmunological and pathological features. They have two pathogenic components, inflammation and neurodegeneration, with different degrees of severy and pathogenic mechanisms. ${ }^{4}$ However, NMO is now recognized to be a different disease ${ }^{5,6}$ with unique pathology and immunopathogenesis that does not respond to tradicional MS immunomodulators such as interferons. ${ }^{1}$

For these reasons, based that $\mathrm{NMO}$ is an autoinmune, inflammatory and demyelinating, disorder ${ }^{3,5,6}$ and on the other hand, in previous surgical experiences with omental transplantation in the chiasmal cistern; ${ }^{7,8}$ we decided to transplant omentum on the chiasm and optic nerves into a patient with severe $\mathrm{NMO}$, to improve visual function.

\section{Case report}

A 45 -year-old right-handed woman, peruvian who was admitted for surgery by bilateral blindness, mydriasis and tetraparesis. In January 2012, she began with right leg cramps and two months later, weakness in both feet and legs, progressive until prostration on Wheel chair during 4 months. No alteration of sphincters. She received gabapentin, prednisone and vitamin $\mathrm{D}$, among others, and walked with help at the month of treatment. In September 2012, she presented again, loss of strength in the lower limbs as well as numbness in the legs until postration. Since May 2013, she suffered deterioration to control the sphincters, as well as she presented a progressive decrease in visual acuity and two months later, weakness in the upper limbs. A tracheotomy was performed in October 2013, due to deterioration of respiratory function and presence of tracheobronchial secretions. During these 23 months of disease, she was attended in several neurological centers in Peru. In all of them, she was diagnosed and treated as NMO.

\section{Examination}

On physical examination, the patient's appearance was appropriate for her age. She was awake and with mild impairment of recent memory. Moderate malnutrition, pallor of skin and conjunctiva, tracheotomy and slough in the sacral region. The respiration was superficial and abdominal predominance. She had Foley Catheter. Her arterial pressure was $100 / 60 \mathrm{~mm} \mathrm{Hg}$; heart rate $84 / \mathrm{min}$ and respiratory rate 22/min. Hemoglobin 10.3 gr\%; glucose $76 \mathrm{mg} \%$; creatinin 0.50 mg \%; leukocytes 4,040/mm cubics, and platelets $295,000 / \mathrm{mm}$ cubics. Bilateral blindness and mydriasis, and absence of pupillary light response in both eyes. The ocular fundi revealed optic atrophy in the papillae and slight loss of retinal nerve fibers. The remainder of the neurological examinatiion showed third-degree spastic tetraparesis of the upper limbs and second-degree of the lower, hyperreflexia in the upper and lower extremities, bilateral Babinski's signs and right palmomentonian reflex. Likewise, she presented left hypoaesthesia up to the $\mathrm{C} 4$ level.

A chest X-ray and electrocardiogram were normal. Preoperative magnetic resonance imaging (RMI) scans showed: 1)mild cortical atrophy in frontal and temporal lobes; 2) mild dilatation in the frontal horns of the ventricular system; 3 ) doubtful intramedullary hypodense area between $\mathrm{C} 3$ and $\mathrm{C} 4$, and 5) atherosclerosis at the supraclinoid carotids and its terminal branches, basilar artery and the V4 segments of the vertebral arteries. The visual evoked potential revealed absence of waves in both eyes. In December 2013, an omental transplantation on the optic chiasma was proposed to the patient and her family to improve visual function. The patient's status was recorded on videotape and she received $300 \mathrm{ml}$ (a globular package) of blood transfusión before surgery.

\section{Operation}

With the diagnosis of severe NMO, an omental transplantation was performed on December 12,2013 without complications. The surgical method was carried out according to a technique described in earlier reports. ${ }^{7-10}$ During surgery we made five important observations: 1) moderate atherosclerosis in the left supraclinoid carotid; 2) marked pallor of the chiasma and optic nerves; 3) doubtful hypotrophy of the chiasma and both optic nerves; 4)several exsanguinated anterior perforating arteries on the dorsal surface of the chiasma (originating from A1 segments of the anterior cerebral arteries), and 5) moderate hypotrophy of the antero-medial portion of the left temporal lobe. Afterwards, a small segment of omentum was placed on the anteromedial surface of the left temporal lobe, and another omental segment was placed over the prechiasmal space and optic chiasma, as well as on the left anterior perforated space. Finally, the surgical wound was closed in standard fashion. During surgery, she received a second globular package.

\section{Postoperative course}

Two hours after surgery, the patient was awake, obeyed orders and without automatic fan. About 24 hours later, the cough reflex 
was better and she presented greater amplitude of the torax during the breathing. Moreover, she presented decreased spasticity in the lower limbs. On the third postoperative day, she showed improvement in recent memory and the voluntary movement of upper limbs improved by $50 \%$ and in lower extremities by $30 \%$. She received soft diet, as well as intravenous antibiotics. A Chest X-ray showed only infiltration parahiliar. Hemoglobin of $11.7 \mathrm{gr} \%$, leukocytes 7,300 /mm cubics (neutrophils, 80\%) and temperature of 38.9 degrees Celsius.

Six days later, she manifested tearing, photophobia and followed with her gaze to the light source. Likewise, the photomotor reflex reappeared and she began to visualize the silhouette of people and things. However, due to respiratory complications, she was transferred to other hospital, where she stayed only two days, because died by bronchopneumonia. A postoperative CT scans performed on the seventh day, it revealed omentum on the optic chiasma and left temporal fossa. The images of the omentum in the chiasmatic cistern were similar to other patients operated by visual impairment, ${ }^{7,8}$ "neurodegenerative diseases" 10,11 and infantile cerebral palsy. ${ }^{12}$

\section{Discussion}

We decided to transplant omental tissue on the chiasm and optic nerves, as well as on left temporal lobe in our patient by the following reasons. First, the chiasm and optic nerves are fasciculi of white matter that embryologically, morphologically and physiologically are similar to the CNS; ${ }^{13-16}$ Second, the target cells for the primary damage in the CNS are different in MS in comparison to NMO. In MS the oligodendrocytes-myelin complex are damaged first, whereas in NMO, the prime target is the astrocyte; ${ }^{4,16-18}$ Third, the target antigen of autoimmunity in NMO is the water channel aquaporin4(AQP4), while in MS no specific autoantigen has been identified. ${ }^{4}$ That is, researchers know that the myelin sheath is directly affected, but they do not know what triggers the immune system to attack the myelin; Fourth, Neurological improvement observed after omental transplantation on the traumatized spinal cord $;{ }^{19,20}$ prechiasmal space, optic chiasma, hypothalamic nuclei, ${ }^{7,21,22}$ and anterior perforated space, ${ }^{7,8,10}$ and Fifth, Unlike of another surgical methods; ${ }^{23}$ our surgical technique can also reduce stress and improve shorth-term memory, sleep disorders and epilepsy after placing omentum on the hypothalamus and antero-medial surface of the left temporal lobe. . $^{70,12,22}$

Although there were only a postoperative follow-up of one week in our patient, she confirmed the results obtained in previous observations, ${ }^{7,8}$ indicating that NMO is also caused by inflammation and ischemia. Because in contrast to this, the omentum caused a rapid development of blood vessels that penetrated directly, vertically and deeply into the underlying nervous tissues (optic nerves, chiasma and hypothalamus) and besides this, anastomosis with adjacent arteries originated from the circle of Willis (anterior perforating arteries and collateral branches originated from the left supraclinoid carotid: anterior choroidal, posterior communicant and ophthalmic arteries). ${ }^{8,10,13,22,24}$ In this way, the hypothalamus, the chiasm, optic nerves, internal capsules and the left temporal lobe are revascularized, and through these omental neovessels, the ischemic parenchyma receives an increase in blood flow, oxygen, neurotransmitters, neurotrophic factors, adipocytokines and omental stem cells. ${ }^{8,18,24}$ Therefore, our surgical technique improved the shortterm memory, and the visual and motora function; as well as caused a reduction in the hyperactivity of the hypothalamo-pituitary-adrenal (HPA) axis observed in patients with MS. ${ }^{25-30}$ Because substantial evidences indicates that stress can precipitate or worsen symptoms of inflammmation in general and more specifically in MS.
Autopsy findings have shown evidence that abrupt astrocyte destruction precedes demyelination in NMO. ${ }^{16,31}$ That is, the astrocyte is first damaged, followed by the oligodendrocyte and finally the axons(demyelination and neuronal loss). Aquaporin-4 antibody is positive in a high porcentaje of NMO patients and it is directed against this water channel richly expressed on foot processes of astrocytes. ${ }^{2,16}$ Thereby, current NMO treatments include general immusuppressive agents, B-cell and plasma exchanges. ${ }^{6,32}$ But there is no prior information of surgical Treatment for this disease. Therefore, the results obtained in our patient are indicate that in NMO there is ischemia in the optic pathway and surrounding structures.

Finally, I wish to comment that the cerebral atherosclerosis found in our patient with $\mathrm{NMO}$ is directly related to the effect of environmental toxins on human glial cells. ${ }^{1,4,11,16,18,22}$ Because atherosclerosis is a consequence of hemodynamic factors and environmental pollutants. ${ }^{33}$

\section{Conclusion}

The neurological improvement obtained in our patient with NMO indicate that the omental tissue placed on the chiasmatic cistern, it revascularized to the chiasm and optic nerves, as well as to the internal capsules and antero-medial portion of the left temporal lobe. Moreover, this clinical case shows that NMO is associated with ischemia in the optic chiasm and surrounding structures, especially the pyramidal pathways at the level of the internal capsules.

\section{Acknowledgments}

None.

\section{Conflicts of interest}

None.

\section{Funding}

None.

\section{References}

1. Kimbrough DJ, Fujihara K, Jacob A, et al. Treatment of neuromyelitis óptica :Review and recommendations. Mult Scler Relat Dis. 2012;1(4):180-187.

2. Sato D, Callegaro D, Lana-Peixoto MA, et al. Treatment of neuromyelitis óptica: An evidence based review. Arq Neuro-Psiquiat. 2012;70(1):59-66.

3. Kowarik MC, Soltys J, Bennett JL. The Treatment of neuromyelitis optica. J Neuroophthalmol. 2014;34(1):70-82.

4. Kawachi I, Lassmann H. Neurodegenerative in multiple sclerosis and neuromyelitis óptica. J Neurol Neurosurg Psychiat. 2017;88(2):137-145.

5. Marignier K, Nicolle A, Watrin Ch, et al. Oligodendrocytes are damaged by neuromyelitis óptica immuno-globuin via astrocyte injury. Brain. 2010;133(8):2578-2591.

6. Howe CL, Kaptzan T, Magaña SM, et al. Neuromyelitis óptica IgG stimulates and immunological response in rat astrocytes cultures. Glia. 2014;62(5):692-708.

7. Rafael H, Moromizato P, Espinoza M, et al. Functional recovery of the injured optic chiasma after omental transplantation. Turk Neurosurg. 1999;9:68-72.

8. Rafael H, Mego R, Alcalá A. Visual improvement following omental transplantation on the ischemic optric chiasma. J Neurol Sci (Turk). 2003;20(3):185-188.

9. Rafael H, Mego R, Moromizato P, et al. Enfermedad de Huntington y ausencia de flujo sanguíneo en las arterias recurrentes de Heubner. Rev Mex Ateroscler. 2000;3:4-8. 
10. Rafael H, Mego R, Moromizato P, Enfermedad de Alzheimer y aterosclerosis del poligono de Willis. Rev Mex Ateroscler. 1999;2:30-33.

11. Rafael H. Omental transplantation for neurodegenerative diseases. Am J Neurodegener Dis. 2014;3(2):50-63.

12. Rafael H, David JO, Vilca AS. Omental transplantation for infantile cerebral palsy. J Neurol Sci (Turk). 2015;32:143-153.

13. Rafael H. Nervios Craneanos. Tercera edición. Editorial Prado, Mexico. 2009. p. 15-68.

14. Grzybowski A, Winiarczyk I. Myelinated retinal nerve fibers (NRNF). Dilemmas related to their influence on visual functional. Saudi J Ophthalmol. 2015;29(1):85-88.

15. Ducke-Elder S. Texbook of ophthalmology. Vol IV: The Neurology of visual motor and optical anamalies. Chapter XLII. Henry Kimpton, London, UK. 1949. p.3473-3617.

16. Sofroniew MV. Astrocyte barrier to neurotoxic inflammmation. Nature Rev Neurosci. 2015; 16(5):249-263.

17. Noseworthy JH, Lucchinetti IC, Rodriguez M, et al. Medical progress: Multiple sclerosis. $N$ Engl J Med. 2000;343(13):938-952.

18. Cannella B, Raine CS. Multiple sclerosis:Cytokines receptor son oligodendrocytes predict innate regulation. Ann Neurol. 2004;55(1):46-57.

19. Abraham J, Paterson A, Bothra M, et al. Omento myelo-synangiosis in the management of chronic traumatic paraplegia. Spinal cord.1987;25:44-49.

20. Rafael H, Polo G. Neurological improvement after omental transplantation on the upper cervical cord. J Trauma Treat. 2015;4:270

21. Rafael H. Rejuvenation after omental transplantation on the optic chiasma and carotid bifurcation. Case Report Clin Pract Rev. 2001;7:48-51.

22. Rafael H. Omental transplantation for neuroendocrinological disorders Am J Neurodegener Dis . 2015;4(1):1-12.
23. Patwardhan RV, Minager M, Kelly RE, et al. Neurological Treatment of multiple sclerosis. Neurol Res. 2009;28(3):320-325.

24. Goldsmith HS. Brain and spinal cord revascularization by omental transposition. Neurol Res. 1994;16(3):159-162.

25. Ysrraelit MC, Gaitan MI, López AS, et al. Actividad del eje hipotálamohipofiso-adrenal durante el curso de la esclerosis multiple. Rev Neurol Arg. 2009;1(1):3-10.

26. Gomez B, Escobar A. Estres y sistema inmune. Rev Mex Neurosci. $2006 ; 7: 30-38$

27. Gouin JP, Hantsoo L, Kiecolt-Glaser JK. Immune dysregulation and chronic stress among older adults: A Review. Neuroimmunomodulation. 2008;15(4):251-259.

28. Lovera J, Reza T. Stress in multiple sclerosis:Review of new developments and future directions. Curr Neurol Neurosci Rep. 2013;13(10):398.

29. Qiu W, Raven S, Wu JS, et al. Hypothalamic lesions in multiple sclerosis. J Neurol Neurosurg Psychiat. 2011;82(7):819-822.

30. Geurts JJG, Bo L, Roosendaal SD, et al. Extensive hippocampal demyelination in multiple. $J$ Neuropathol Exp Neurol. 2007;66(9):819-827.

31. Barnett MH, Prineas JW, Buckland ME, et al. Massive astrocyte destruction in neuromyelitis optica despite natalizumab therapy. Mult Scler. 2012;18(1):108-112.

32. Papadopoulos MC, Bennett JL, Verkman AS. Treatment of neuromyelitis optica: State-of-the art and emerging therapies. Nat Rev Neurol . 2014;10(9):493-506.

33. Rafael H. Aspirin against atherosclerotic intracranial arterial stenosis. $J$ Neurol Neurophysiol. 2016;7(6):403. 